\title{
Capacidade de uso da terra e abatimento de erosão hídrica em propriedades agrícolas do sul do Rio Grande do Sul
}

\section{Land use capability and reduction of water erosion in agricultural properties in the south of Rio Grande do Sul, Brazil}

\section{Margareth Andrade dos Reis TAVARES ${ }^{1}$; Maria Cândida Moitinho NUNES ${ }^{2}$; Vitor Emanuel Quevedo TAVARES ${ }^{3}$; Flavia Fontana FERNANDES ${ }^{4}$; Letícia Penno de SOUSA ${ }^{5}$}

${ }^{1}$ MSc. Universidade Federal de Pelotas. Faculdade de Agronomia Eliseu Maciel. PPG Manejo e Conservação do Solo e da Água margatav@yahoo.com.br

${ }^{2}$ Autor para correspondência. Drª Universidade Federal de Pelotas-Faculdade de Agronomia Eliseu Maciel. Departamento de Solos. PPG Manejo e Conservação do Solo e da Água. Campus Universitário s/n. Capão do Leão - RS, Brasil - CEP: $96010-$ 610 nunes.candida@gmail.com

${ }^{3}$ Dr. Universidade Federal de Pelotas-Faculdade de Agronomia Eliseu Maciel. Departamento de Engenharia Rural. PPG Manejo e Conservação do Solo e da Água veqtavares@yahoo.com.br

${ }^{4} \mathrm{Dr}^{\mathrm{a}}$. Universidade Federal de Pelotas. Faculdade de Agronomia Eliseu Maciel. Departamento de Solos f_flavia_fernandes@yahoo.com.br

${ }^{5}$ Dra . Empresa Brasileira de Pesquisa Agropecuária-EMBRAPA Clima Temperado, Pelotas-RS. leticia.penno@embrapa.br

Recebido em: 07-07-2020; Aceito em: 20-10-2020

\section{Resumo}

Sistemas de uso e manejo do solo adotados de forma inadequada podem comprometer a qualidade dos solos e dos corpos hídricos. O objetivo desse estudo foi determinar a capacidade de uso da terra e o percentual de abatimento de erosão, decorrentes do uso e manejo adequados do solo para a bacia hidrográfica do arroio Epaminondas. Foram selecionadas três propriedades rurais da bacia, subdivididas em glebas homogêneas. Foi realizado o levantamento dos fatores limitantes de cada gleba, bem como análises físicas e químicas dos solos. Foi classificada a capacidade de uso da terra, identificados os conflitos de uso e calculado o percentual de abatimento da erosão. A profundidade efetiva e o gradiente textural foram os principais fatores limitantes observados, responsáveis pela classificação de $87,69 \%$ da área na classe IV de capacidade de uso da terra. Da área agrícola em estudo, 53,42\% estão sobreutilizadas, ou seja, em conflito de uso. A implantação de um projeto de pagamento por serviços ambientais, com mudança no uso da terra e substituição do cultivo convencional por sistemas conservacionistas, pode proporcionar redução de $59,74 \%$ da erosão nessas áreas agrícolas. Nas áreas atualmente com hortaliças e pousio, a adoção da prática de plantio direto em hortaliças, com cultivo em nível e em rotação com plantas de cobertura, além da recuperação das pastagens, pode promover abatimento da erosão em, aproximadamente, $51 \%$.

Palavras-chave adicionais: conflitos de uso; conservação do solo; impacto ambiental; serviços ambientais; uso e manejo do solo.

\begin{abstract}
Inappropriate land use and management systems degrade the soil and water quality. This study aimed to determine the land use capability and estimate the reduction of soil erosion, resulting from the adoption of better land use and management practices, for the Epaminondas stream watershed. Three representative farms were selected in the study area and split into homogeneous plots. A survey of the limiting factors of each plot was carried out, as well as physical and chemical analyzes of the soils. For each plot were undertaken a land use capability classification, conflict of use identification and a soil erosion percentual reduction estimate. The main limiting factors observed were shallow effective soil depth and textural gradient, which were responsible for $87.69 \%$ of the area being classified as class IV of land use capability. It was found that $53.42 \%$ of the agricultural area under study are overused, which characterizes conflict of use. The implementation of a payment for environmental services project, rewarding farmers for more adequate land use and replacement of conventional cultivation by conservationist systems, can provide a $59.74 \%$ reduction in erosion in these agricultural areas. In areas currently with vegetables and fallow, the adoption of the no-till vegetables production, combined with contour cropping and rotation with cover crops, in addition to pasture improvement, can promote a soil erosion reduction of approximately $51 \%$.
\end{abstract}

Additional keywords: environmental impact; environmental services; land use and management; soil conservation; use conflicts. 


\section{Introdução}

O solo é um dos principais recursos naturais utilizados nas atividades agrícolas e, de acordo com o uso e os sistemas de manejo adotados, pode-se comprometer a sua capacidade produtiva e a qualidade do ambiente. $O$ processo de crescente urbanização de áreas agrícolas, associado ao uso e manejo inadequado do solo, tem acarretado na aceleração da hídrica, levando à redução da produtividade, da renda e de segurança alimentar e nutricional de agricultores familiares, além de configurar situações de conflito do uso da terra.

O sistema de classificação da Capacidade de Uso das Terras (CUT) é recomendado, principalmente, para fins de planejamento de práticas de conservação do solo, em nível de propriedades, empresas agrícolas ou para pequenas bacias hidrográficas (Flauzino et al., 2016). Sua ampla adaptação para o panorama brasileiro torna a sua aplicação adequada para compreender o cenário de degradação de terras agrícolas (Cunha \& Pinton, 2012).

Ribeiro et al. (2019) estudaram a aptidão e capacidade de uso das terras do Vale do Paraíba Paulista e afirmam que a avaliação pelo sistema de capacidade de uso da terra (Sistema CUT), no qual são avaliadas características relacionadas às limitações de solo, erosão, água e clima, apesar de certa complexidade para ser interpretado, possibilita maior precisão na classificação de uso, facilitando o estabelecimento de práticas a serem preconizadas no manejo. Esse sistema estabelece o limite máximo de intensidade de uso da terra (Servidoni et al., 2016) e tem por objetivo estabelecer o aproveitamento das condições da terra, com um mínimo de perdas por erosão, baseando-se em um detalhamento expressivo dos fatores que possam influenciar na estruturação e composição do ambiente, tais como solo, relevo, erosão e clima, entre outros, permitindo que o planejamento de uso racional do meio ocorra sobre bases mais confiáveis (Campos et al., 2010).

O sistema CUT leva em consideração as formas de uso agrícola racional, sem causar o empobrecimento do solo e a degradação ambiental (Lepsch et al., 2015). Esse sistema se baseia em fatores relacionados ao solo, relevo, erosão, uso atual da terra e excesso de água, segundo os quais estabelece classes de uso das terras para culturas agrícolas, pastagens plantadas, reflorestamento (silvicultura) ou para áreas de preservação permanente.

O planejamento de atividades agrícolas e de pecuária, principalmente em escala de propriedade agrícola, deve ser de acordo com a capacidade de uso da terra, para que se estabeleça seu aproveitamento com máxima produtividade, aliado à conservação do solo e da água. Quando relacionado ao uso e ocupação atual, esse sistema permite identificar as áreas em que o uso está em desacordo com a capacidade de suporte natural das terras (Aires et al., 2017), o que caracteriza os conflitos de uso.

Os conflitos de uso da terra ocorrem a partir da ocupação pelas atividades antrópicas de locais que não são adequados, seja por características físicas do solo, seja por relevância ambiental do ponto de vista da conservação dos recursos naturais (Kreitlow et al., 2016). A identificação destes conflitos é determinada por meio do confronto entre a capacidade de uso da terra e o uso atual, sendo este o primeiro passo para o estabelecimento de medidas de conservação que possam ser usadas para mitigar os impactos existentes nas propriedades agrícolas e na bacia. A identificação de serviços ambientais, afetados pelos conflitos no uso da terra, pode auxiliar no estabelecimento de prioridades, visando a definição das medidas de conservação e recuperação das áreas a serem inseridas em programas de compensação ou retribuição pela preservação ou restauração de serviços ambientais (Campos et al., 2016).

Em 2003, a Agência Nacional de Águas (ANA) desenvolveu o Programa Produtor de Água (PPA), tendo como foco o estímulo à política de pagamento por serviços ambientais voltada à proteção dos recursos hídricos no Brasil. O pagamento por serviços ambientais é um instrumento baseado no mercado para financiamento da conservação, que considera os princípios do usuário-pagador e provedor-recebedor, pelos quais aqueles que se beneficiam dos serviços ambientais (como os usuários de água limpa, por exemplo) devem pagar por eles, e aqueles que contribuem para a geração desses serviços (como os usuários de terra a montante) devem ser compensados por proporcioná-los (Engel et al., 2008).

O PPA tem como fundamento a concessão de incentivos financeiros a produtores rurais, que, de forma voluntária, implantem projetos de conservação do solo em suas propriedades, assim como o uso de espécies vegetais, incluindo as nativas, para a recuperação ambiental. Um dos objetivos desse programa é reduzir os níveis de poluição difusa rural em mananciais estratégicos para o país, principalmente os decorrentes de processos de erosão (ANA, 2012). O PPA utiliza o modelo USLE - Universal Soil Loss Equation (Wischmeier \& Smith, 1978) de modo simplificado, apoiando-se apenas na variação dos fatores antrópicos, uso e manejo do solo e de culturas e práticas conservacionistas para determinação dos valores de pagamento por serviços ambientais. Assim, estima-se o Percentual de Abatimento da Erosão a partir dos cenários de redução dos fatores Cultura e Práticas conservacionistas adequando-se o valor de pagamento por serviços ambientais por unidade de área, conforme o enquadramento dos valores de percentual de abatimento da erosão (Rodrigues et al., 2011).

A identificação de áreas agrícolas fora da CUT, em conflito de uso, poderá auxiliar no planejamento e indicação do destino mais adequado para a terra, evitando que ocorra a sua degradação, muitas vezes irreversível. Essas ações podem aumentar o percentual de abatimento de erosão e contribuir com a retribuição aos produtores rurais, por atividades conservacionistas em suas propriedades.

No município de Pelotas, aproximadamente $50 \%$ da água tratada é proveniente da Estação de 
Tratamento de Água Santa Bárbara, sendo o arroio Epaminondas um importante afluente do reservatório desta estação. A crescente urbanização de Pelotas tem aumentado a pressão sobre os recursos naturais, especialmente em regiões periurbanas, como é o caso da bacia hidrográfica do arroio Epaminondas. O inadequado uso e ocupação dessas áreas tem levado à aceleração do processo erosivo, com redução do perfil produtivo do solo e comprometimento da qualidade $\mathrm{e}$ quantidade da água, devido ao transporte de sedimentos, agrotóxicos e nutrientes, afetando também os custos de captação e tratamento de água.

A mudança no uso da terra, nas práticas e/ou manejo do solo, quando a área estiver fora de sua capacidade de uso, aumenta o percentual de abatimento de erosão e, consequentemente, a retribuição por serviços ambientais. Nesse sentido, objetivou-se determinar a capacidade de uso da terra e o percentual de abatimento de erosão na bacia hidrográfica do arroio Epaminondas, decorrente de recomendações relativas ao adequado uso e manejo adequados do solo.

\section{Material e métodos}

\section{Localização da área de estudo}

O estudo foi realizado em três propriedades agrícolas localizadas em Pelotas-RS (Figura 1), distribuídas na bacia hidrográfica do arroio Epaminondas, que é o afluente com maior área de contribuição para o reservatório da barragem Santa Bárbara (Figura 2), onde é feita a captação de água para a Estação de Tratamento de Água Santa Bárbara, que, atualmente, é a principal fonte de água potável para o município de Pelotas.

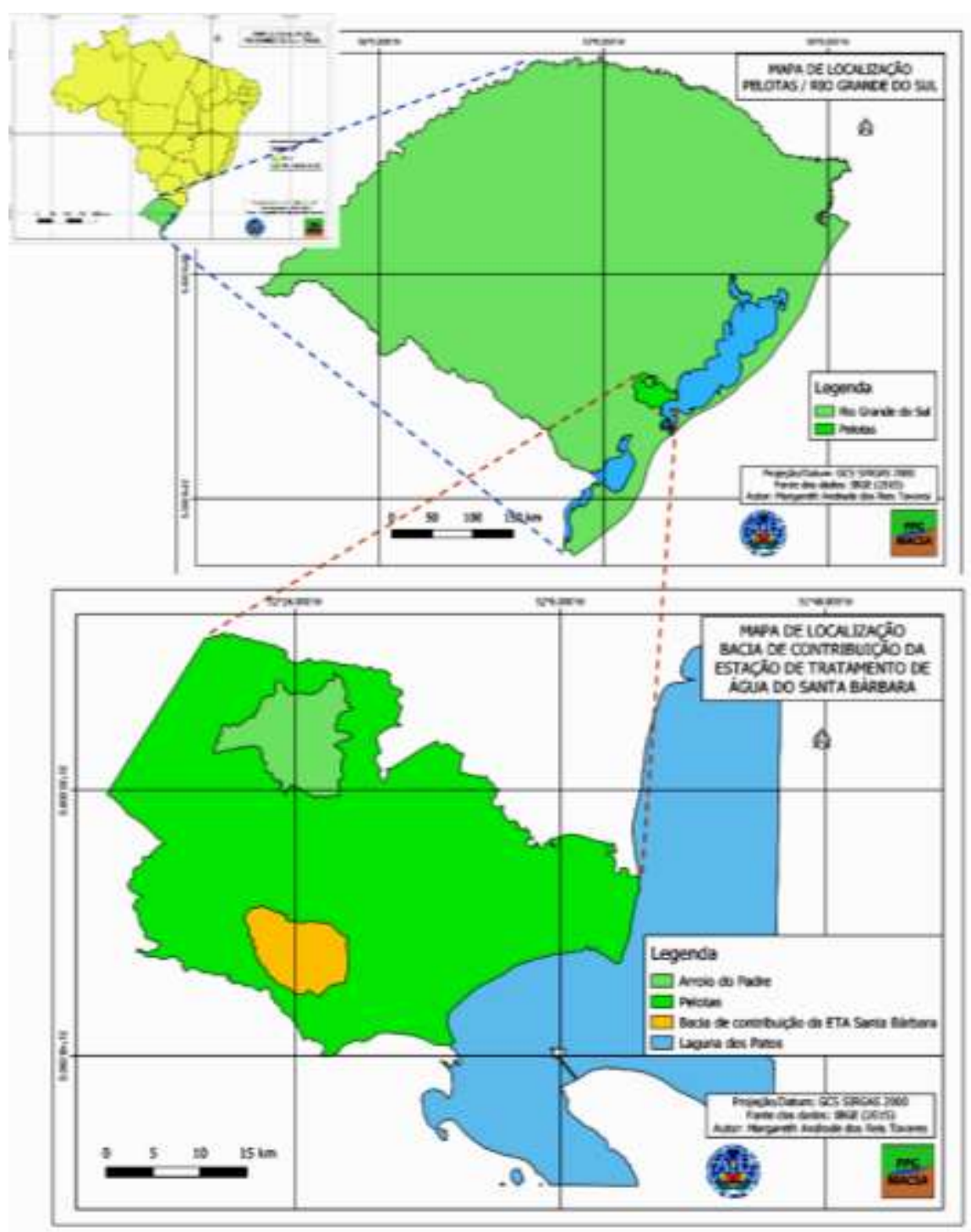

Figura 1 - Mapa de localização da bacia de contribuição da barragem Santa Bárbara, Pelotas (RS). Location map of the contribution basin of the Santa Bárbara dam, Pelotas (RS). 


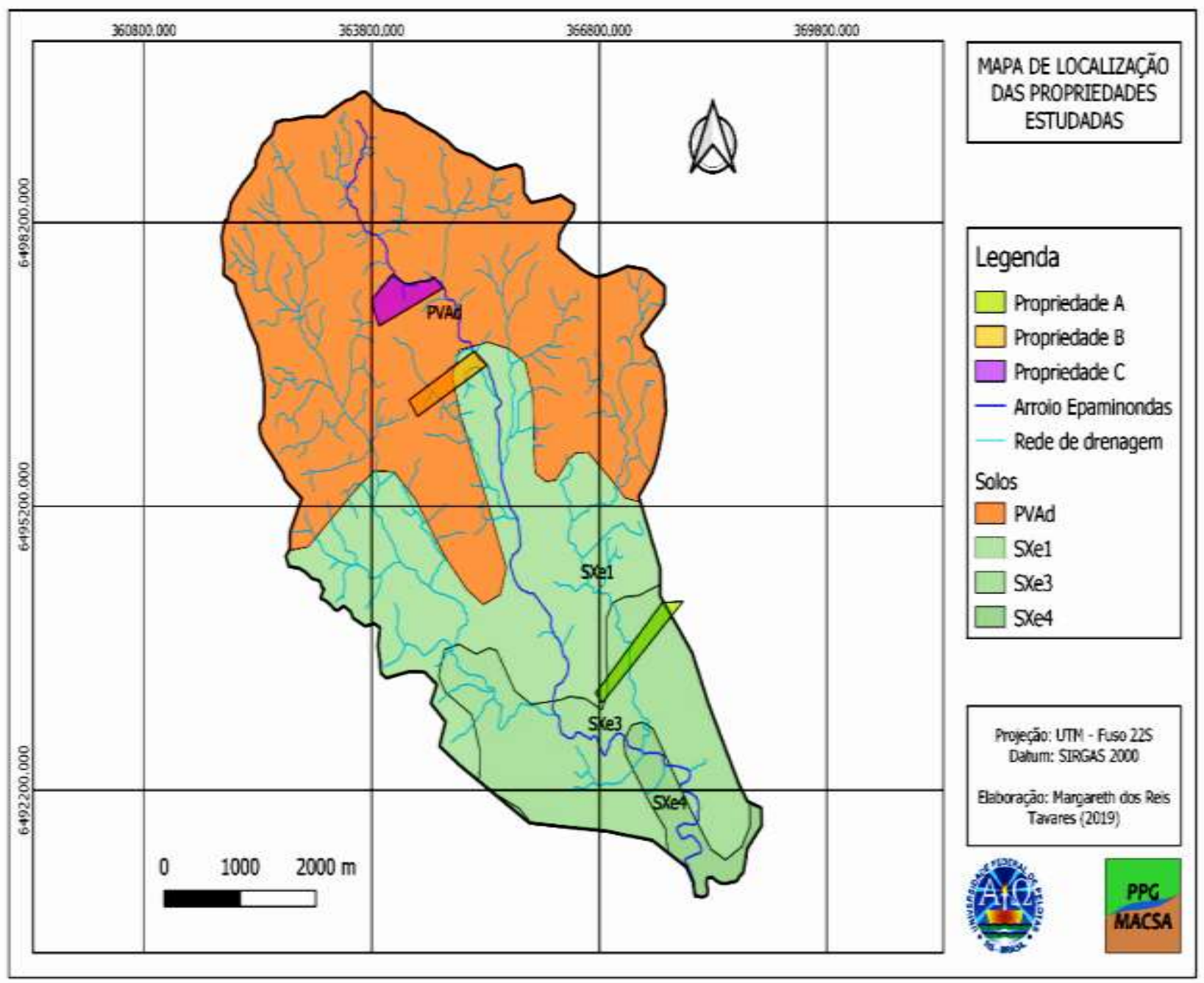

PVAd - Argissolo Vermelho-Amarelo Distrófico e Eutrófico, Tb, com Argissolo Vermelho-Amarelo Planossólico indiscriminado; SXe1 - Planossolo Háplico Eutrófico, Ta, com Argissolo Vermelho-Amarelo Planossólico indiscriminado; SXe3 - Planossolo Háplico Eutrófico, Ta, com Planossolo Nátrico e Gleissolo indiscriminados; SXe4 - Planossolo Háplico Eutrófico, Ta, fase erodida, com Planossolo Nátrico e Gleissolo indiscriminados.

Figura 2 - Mapa de localização das propriedades agrícolas na bacia hidrográfica do arroio Epaminondas em Pelotas (RS) e das classes de solos mais representativas. Map of location of agricultural properties in the watershed of the Epaminondas stream in Pelotas (RS) and of the most representative soil classes.

O critério de escolha das propriedades se baseou na proximidade ao curso d'água principal e na posição ao longo da bacia, considerando-se o relevo e o tipo de solo mais comum. As propriedades em estudo representam as posições alto, médio e baixo Epaminondas.

A bacia hidrográfica do arroio Epaminondas possui $33,3 \mathrm{~km}^{2}$ e está localizada entre as coordenadas $31^{\circ} 37^{\prime} 51,19^{\prime \prime} S$ e $31^{\circ} 42^{\prime} 29,44^{\prime \prime} S$ de latitude e $52^{\circ} 22^{\prime} 58,80^{\prime \prime} \mathrm{O}$ e $52^{\circ} 27^{\prime} 26,19^{\prime \prime}$ O de longitude. O clima da região é do tipo subtropical úmido (Cfa), conforme a classificação climática de Köppen, com médias de $8,6^{\circ} \mathrm{C}$ no mês mais frio e de $19,3^{\circ} \mathrm{C}$ no mês mais quente. A precipitação média não apresenta sazonalidade bem definida, sendo fevereiro o mês mais chuvoso $(158,2 \mathrm{~mm})$ e outubro o mês menos chuvoso (104,5 mm) (Wrege et al., 2012).

Para a delimitação da bacia hidrográfica do arroio Epaminondas, das propriedades e glebas de estudo, foram empregadas bases de dados do Instituto Brasileiro de Geografia e Estatística, visitas in loco e imagens de satélite Maxar Technologies obtidas a partir do programa livre Google Earth ${ }^{\circledR}$, utilizando o programa computacional livre $Q G / S^{\circledR}$, versão 3.4.8 (Madeira), para o geoprocessamento dos dados.

A classificação dos solos das áreas do estudo (Figura 1) foi feita de acordo com os mapas de solos da Embrapa (Flores et al., 2009), que foram sobrepostos ao mapa dos limites da bacia. A nomenclatura das classes de solo foi atualizada, de acordo com o Sistema Brasileiro de Classificação do Solo da Embrapa (Santos et al., 2018).

Na tTabela 1 são apresentadas as áreas absolutas de cada propriedade, em hectares, bem como as áreas relativas no estudo e suas respectivas classes de solos. 
Tabela 1 - Áreas absolutas e relativas das propriedades agrícolas do estudo e respectivas classes de solos. Absolute and relative areas of the agricultural properties of the study and respective classes of soils.

\begin{tabular}{lcccr}
\hline \multirow{2}{*}{ Propriedade } & \multicolumn{2}{c}{ Área } & \\
\cline { 2 - 5 } & Absoluta (ha) & Relativa (\%) & Classe de solo & Área (ha) \\
\hline A & 22,70 & 32,76 & SXe1 $^{1}$ & 2,11 \\
& & & SXe3 $^{2}$ & 20,59 \\
B & 21,72 & 31,35 & SXe1 $^{1}$ & 8,81 \\
C & 24,87 & 35,89 & PVAd $^{3}$ & 12,91 \\
\hline TOTAL & 69,29 & 100,00 & & 24,87 \\
\hline
\end{tabular}

${ }^{1}$ Planossolo Háplico Eutrófico, Ta, com Argissolo Vermelho-Amarelo Planossólico indiscriminado. ${ }^{2}$ Planossolo Háplico Eutrófico, Ta, com Planossolo Nátrico e Gleissolo indiscriminados. ${ }^{3}$ Argissolo Vermelho-Amarelo Distrófico e Eutrófico, Tb, com Argissolo Vermelho-Amarelo Planossólico indiscriminado.

\section{Caracterização dos fatores limitantes das glebas}

A subdivisão das propriedades em glebas homogêneas considerou o tipo de solo, a topografia, a vegetação, os sistemas de cultivo e o histórico de uso. Em cada gleba foram realizadas coletas de amostras de solo no campo e identificação dos fatores limitantes para a determinação das classes de capacidade de uso da terra (CUT).

Após a subdivisão das glebas foram realizados trabalhos de campo para o levantamento do meio físico, com a coleta de informações sobre critérios diagnósticos, como profundidade efetiva, textura, permeabilidade, declividade, erosão hídrica e uso atual. O levantamento do meio físico objetivou conhecer as principais características da terra, suas potencialidades e limitações.

Nas três propriedades, foram coletadas amostras de solo em 11 pontos de cada gleba. Foram caracterizadas 25 glebas, sendo 11 glebas na propriedade $A, 8$ na propriedade $B$ e 6 na propriedade $C$, totalizando 275 pontos representativos. Em cada gleba, foi aberta uma trincheira, para a identificação dos fatores limitantes, conforme os procedimentos descritos em Lepsch et al. (2015). As amostras de solo coletadas em cada ponto foram encaminhadas para laboratório, visando determinar atributos físicos e químicos básicos, como textura, matéria orgânica e $\mathrm{pH}$. Para a determinação da declividade do terreno foram realizados levantamentos de campo e interpretação de imagens de satélite do programa Google Earth ${ }^{\circledR}$ (2018), que fornece informações planialtimétricas, por meio da ferramenta "Perfil de elevação", conforme sugerido por Lepsch et al. (2015).

\section{Capacidade de uso da terra e conflitos de uso}

A determinação da CUT foi realizada conforme o método proposto por Lepsch et al. (2015). Também considerou o enquadramento descrito em Lopes e Campos (2019), os quais avaliaram a CUT da subbacia do Córrego Maria Comprida por meio de Sistemas de Informações Geográficas.

Para o presente estudo foram analisadas somente áreas de uso agrícola, não sendo consideradas as áreas de construções, reserva legal e Áreas de
Preservação Permanente. Os usos da terra foram classificados em: subutilização da terra, utilização racional da terra (sem conflito) e sobreutilização da terra.

A identificação dos conflitos de uso foi realizada mediante o confronto da CUT com o uso atual. Para as áreas que se encontravam em conflito de uso, foram propostas alternativas de uso e manejo conservacionista. A classificação da CUT (Lepsch et al., 2015) é estabelecida por uma ordenação em níveis hierárquicos, estruturada nas categorias: grupos de capacidade de uso (A, B e C), baseados nos tipos de intensidade de uso das terras; classes de capacidade de uso (I a VIII), baseadas no grau de limitação de uso; subclasses de capacidade de uso (e, s, a, c), de acordo com a natureza da limitação; e unidades de capacidade de uso, referentes às condições específicas que afetam o uso e manejo da terra; além de seus respectivos critérios determinantes, que levam em conta o nível mais generalizado para o mais detalhado.

\section{Percentual de Abatimento da Erosão}

Para o cálculo do percentual de abatimento da erosão nas propriedades da bacia hidrográfica foi usado o método elaborado por Chaves et al. (2004a), que adota a simplificação da USLE como modelo ideal, considerando que vários dos parâmetros da USLE são constantes antes e depois da provável implantação do projeto conservacionista nas propriedades. A USLE (Wischmeier \& Smith, 1978) é dada pela seguinte expressão:

$A=R K L S C P$

Em que: $A=$ perdas de solo por erosão hídrica, em $\mathrm{t} \mathrm{ha}^{-1}$ ano-1; $\mathrm{R}=$ fator erosividade da chuva, $\mathrm{MJ} \mathrm{mm} \mathrm{ha}^{-1} \mathrm{~h}^{-1}$; $\mathrm{K}=$ fator erodibilidade do solo, $\mathrm{t}$ ha $\mathrm{h} \mathrm{ha}^{-1} \mathrm{MJ}^{-1} \mathrm{~mm}^{-1}$; $\mathrm{L}=$ fator comprimento do declive, adimensional; $\mathrm{S}=$ fator grau do declive (declividade), adimensional; $\mathrm{C}=$ fator manejo e cobertura vegetal, adimensional; $\mathrm{P}=$ fator práticas conservacionistas, adimensional.

Os fatores da USLE R, K, L e S foram considerados constantes antes e depois da implantação do projeto conservacionista. Os fatores $\mathrm{C}$ e $\mathrm{P}$, que podem ser alterados de forma antrópica, foram usados para a estimativa do percentual de abatimento da erosão. 
Considerando o método de Chaves et al. (2004a), o produto CxP foi denominado Z. Após, dividida a perda de solo sob a condição proposta $\left(A_{1}\right)$ pela perda sob a condição inicial $\left(A_{0}\right)$ e cancelados os termos constantes na equação da USLE, se obtém a seguinte equação:

$A_{1} / A_{0}=Z_{1} / Z_{0}$

Em que: $A_{1}=$ estimativa da perda de solo após a implantação do projeto (t ha- ${ }^{-1}$ ano $^{-1}$ ); $A_{0}=$ estimativa da perda de solo antes da implantação do projeto ha $\left.{ }^{-1} a^{-1}\right) ; Z_{1}=$ valor do parâmetro $Z$ após a implantação do projeto; $Z_{0}=$ valor do parâmetro $Z$ antes da implantação do projeto.

A estimativa do abatimento da erosão foi calculada pela equação:

$\operatorname{PAE}(\%)=100\left(1-\mathrm{A}_{1} / \mathrm{A}_{0}\right)$

Em que: $P A E$ = percentual de abatimento de erosão;

Substituindo o termo $A_{1} / A_{0}$ da equação (3) pela equação (2), obtém-se:

$\operatorname{PAE}(\%)=100\left(1-Z_{1} / Z_{0}\right)$
Para o parâmetro $\mathrm{C} \times \mathrm{P}(=\mathrm{Z})$, foram utilizados os valores de $Z$ disponibilizados por vários autores, referentes a diversos usos e manejos, convencionais e conservacionistas, conforme Chaves et al. (2004a). Esses valores encontram-se listados na tabela 2, apresentando a situação inicial $\left(Z_{0}\right)$ e a situação proposta $\left(Z_{1}\right)$.

Para os valores de $Z_{0}$ e $Z_{1}$ foi calculada a média ponderada pelo tempo de uso entre os valores referentes aos usos de inverno e verão. Para o cálculo da estimativa do percentual de abatimento da erosão, as alternativas foram propostas considerando a CUT, a vocação do produtor, a questão econômica e a aplicação prática. Em função da falta de valores de $Z_{1}$ na bibliografia, para o uso alternativo e conservacionista com rotação de culturas, foi adotado o valor de $Z_{1}$ indicado para pastagem recuperada. Para o pousio de inverno, foi adotado o valor de $Z_{0}$ referente à pastagem degradada. Para valorizar os serviços ecossistêmicos, não foram realizadas sugestões de mudança no uso para as áreas com mata nativa.

Tabela 2 - Valores de $Z_{0}$ para usos e manejos convencionais e $Z_{1}$ para usos e manejos conservacionistas. Values of $Z_{0}$ for conventional uses and managements and $Z_{1}$ for conservationist uses and managements.

\begin{tabular}{lccc}
\hline \multicolumn{3}{c}{ Manejo } \\
\hline Convencional & $Z_{0}$ & Conservacionista & $Z_{1}$ \\
\hline Grãos & 0,25 & Grãos, rotação & 0,20 \\
Algodão & 0,62 & Grãos, em nível & 0,13 \\
Mandioca & 0,62 & Grãos, rotação, em nível & 0,10 \\
Cana-de-açúcar & 0,10 & Grãos, faixas vegetadas & 0,08 \\
Batata & 0,75 & Grãos, cordões vegetação & 0,05 \\
Café & 0,37 & Grãos, plantio direto & 0,03 \\
Hortaliças & 0,50 & Algodão, mandioca, rotação & 0,40 \\
Pastagem degradada & 0,25 & Algodão, mandioca, nível & 0,31 \\
Capoeira degradada & 0,15 & Algodão, mandioca, plantio direto & 0,04 \\
Cascalheira, solo nu & 1,00 & Cana, em nível & 0,05 \\
Silvicultura & 0,03 & Cana, em faixas & 0,03 \\
& & Batata, em nível & 0,38 \\
& & Batata, em faixas & 0,22 \\
& & Café, em nível & 0,19 \\
& & Café, em faixas & 0,11 \\
& & Hortaliças, em nível & 0,25 \\
& & Pastagem recuperada & 0,12 \\
& & Pastagem, rotação com grãos & 0,10 \\
& & Reflorestamento denso & 0,01 \\
& & Reflorestamento ralo & 0,03 \\
\hline
\end{tabular}

Derpsch (2002); De Maria \& Lombardi Neto (1997); Margolis et al. (1985); Bertoni \& Lombardi Neto (1990); Leprun (1983); Paula Lima (2003). Fonte: Adaptado de Chaves et al. (2004a).

\section{Resultados e discussão}

\section{Principais fatores limitantes}

A análise dos dados permitiu verificar que os principais fatores limitantes ao uso das terras em propriedades da bacia hidrográfica do arroio Epaminondas estão associados à profundidade efetiva dos solos e à declividade do terreno (Tabela 3). Assim, constatou-se que $74,40 \%$ da área estudada é composta por solos rasos, enquanto $25,60 \%$ apresentam solos moderadamente profundos.

A predominância de solos rasos, associada à 
existência de horizonte $B$ textural, pode fazer com que estes tenham limitação de volume de solo para armazenagem de água e nutrientes para ser explorado pelo sistema radicular das plantas, o que tem como consequência menor grau de recarga de aquíferos subterrâneos e superficiais dentro da bacia do arroio Epaminondas. Em períodos de elevada precipitação, podem facilmente atingir a saturação, resultando em maiores volumes de escoamento superficial e, portanto, maiores riscos de ocorrência de erosão hídrica. Por outro lado, em épocas de déficit de hídrico, terão menor capacidade de armazenamento de água, podendo passar rapidamente de um estado de saturação para um estado de estresse hídrico.

Tabela 3 - Distribuição relativa das classes de profundidade efetiva, de declividade e uso atual referentes às glebas das propriedades da bacia hidrográfica do arroio Epaminondas. Relative distribution of classes of effective depth, slope and current use, referring to the estates of the watershed of the Epaminondas stream.

\begin{tabular}{lc}
\hline Classes de profundidade & Área relativa (\%) \\
\hline Raso $(0,25$ a $0,50 \mathrm{~m})$ & 74,40 \\
Moderadamente profundo $(0,50$ a $1,00 \mathrm{~m})$ & 25,60 \\
\hline Classes de declividade & Área relativa (\%) \\
\hline A (declives de 0 a 2\%) & 33,05 \\
B (declives entre 2 e 5\%) & 32,19 \\
C (declives entre 5 e 10\%) & 34,76 \\
\hline Uso atual & Área relativa (\%) \\
\hline Campo nativo & 3,41 \\
Horticultura & 2,73 \\
Lavoura anual & 0,74 \\
Mata nativa & 2,32 \\
Pousio de inverno & 37,45 \\
Silvicultura & 28,46 \\
Outros usos & 24,89 \\
\hline
\end{tabular}

As classes de declividade estão bem distribuídas ao longo da bacia. As menores declividades (de 0 a $2 \%$ ) predominam na parte baixa da bacia (baixo Epaminondas), que apresenta declive médio de 1,48\%. Nesta classe de declive, as terras são passíveis de utilização por máquinas agrícolas e não estão propícias à erosão hídrica significativa, pois o escoamento superficial é muito lento ou lento. Contudo, nessas áreas há risco de excesso hídrico, o que dificulta a drenagem da água e o adequado desenvolvimento de algumas culturas.

A parte mais inclinada da bacia, no alto curso do Epaminondas, apresenta declive médio de 6,55\%. Esta classe de declividade é compreendida por porções de encostas com superfície moderadamente inclinadas. É necessário se atentar às características da área onde este solo está inserido, já que o uso de terras em áreas declivosas pode incorrer em processos erosivos acelerados, gerando sérios problemas ambientais relacionados a perda de solos e nutrientes por erosão e à contaminação de corpos d'água, como foi apontado na avaliação de um sistema de capacidade de uso em uma microbacia no interior de Minas Gerais, por Aires et al. (2017).

Considerando-se os usos da terra nas 25 glebas das propriedades estudadas (Tabela 3), nota-se que o pousio de inverno predomina $(37,45 \%)$ quando há cultivos anuais. Ele pode ser observado na sequência de culturas como soja (Glycine max (L.) Merr.), abóbora (Cucurbita moschata Duch.) e alface (Lactuca sativa L.). Em segundo lugar, constatou-se o plantio de eucalipto, com 28,46\%. Estes usos ocupam mais de $60 \%$ da área de estudo e são adotados pelos produtores, por questões econômicas, culturais e familiares, passados de geração a geração, com predomínio de manejos convencionais, como aração e gradagem. A abóbora e a alface são culturas que geram renda a curto prazo, são relativamente fáceis de conduzir e têm mercado garantido para os produtores da região. $O$ cultivo da soja nessas pequenas propriedades tem sido uma alternativa de renda, devido à possibilidade de mecanização para cultivo, pois diminui a penosidade do trabalho, em relação ao cultivo de hortaliças. Na região, a mão de obra é escassa, função do êxodo rural, do envelhecimento dos produtores e da falta de sucessão familiar, situação muito comum no Brasil. Ressalta-se que o cultivo da soja nessas pequenas propriedades rurais não é adequado, tanto pela capacidade de uso das terras quanto pelo fato de exigir uma escala maior de produção para ser rentável.

\section{Capacidade de uso da terra e conflitos de uso}

De acordo com os resultados obtidos, apenas $1,38 \%$ da área de estudo se enquadrou na classe III (Tabela 4) e subclasse "s" do grupo A, onde se encontram as terras de moderada a boa produtividade $\mathrm{e}$ próprias para cultivo de culturas anuais, porém com intensas práticas de controle da erosão, associadas à correção da acidez e da fertilidade (Lepsch et al., 2015). 
Tabela 4 - Capacidade de uso da terra e conflitos de uso em glebas de propriedades agrícolas da bacia hidrográfica do arroio Epaminondas, Pelotas (RS). Capacity of land use and conflicts of use in agricultural property plots in the Epaminondas stream basin, Pelotas (RS).

\begin{tabular}{lc}
\hline Classe de capacidade de uso & Área relativa (\%) \\
\hline III & 1,38 \\
IV & 87,69 \\
V & 10,93 \\
\hline Classe de conflito & Área relativa (\%) \\
\hline Sem conflito & 46,58 \\
Sobreutilizado & 53,42 \\
\hline
\end{tabular}

As glebas enquadradas na classe IV apresentam limitação à permeabilidade do solo, que é uma característica comum em Argissolos e Planossolos, devido à presença de gradiente textural. Quando as terras desta classe são cultivadas, estão sujeitas a severos riscos de degradação, mesmo com culturas adaptadas, o que requer intensas e complexas medidas de conservação ou melhoramento dos solos, a fim de garantir produção média a elevada (Lepsch et al., 2015).

A maior parte da área em estudo (87,69\%) se enquadrada na classe IV e subclasse " $s$ " do grupo A. Essas terras não se prestam para o cultivo contínuo e regular de culturas anuais climaticamente adaptadas, permitindo sua utilização em períodos curtos ou em rotação quando adequadamente protegidas. São consideradas como de moderada produtividade, próprias para culturas perenes. Ocasionalmente podem ser utilizadas para culturas anuais, desde que adotadas práticas intensas de controle da erosão (Lepsch et al., 2015). Nas glebas avaliadas, essa classificação se deve, principalmente, a pouca profundidade efetiva e presença de gradiente textural, o que evidencia restrições na escolha dos cultivos. As glebas pertencentes à classe IV deveriam ser usadas com cultivos ocasionais ou limitados, com rotação de culturas e cultivo em nível. $\mathrm{O}$ uso de culturas anuais, sob manejo inadequado, se caracteriza em sobreuso, pois nessas áreas o potencial de erosão será maior.

A classe $V$ do grupo $B$ e subclasse " $s$ " foi encontrada em 10,93\% da área. As terras dessa classe não têm risco de erosão ou têm pequeno risco, devido à baixa declividade, mas possuem outras limitações, como pequena profundidade efetiva do solo e drenagem deficiente. Essas limitações não podem ser removidas, fazendo com que seu uso seja limitado apenas para pastagens, reflorestamentos (silvicultura) ou preservação permanente. Ressalta-se que para casos especiais, de cultivos sob condições de alagamento, como no caso do arroz irrigado, não há limites para seu cultivo.

Da área total em estudo, $75,10 \%$ é utilizada para fins agrícolas. A partir da comparação entre o uso atual e a capacidade de uso, observa-se que $53,42 \%$ da área agrícola está sobreutilizada, ou seja, em conflito de uso. Lopes \& Campos (2019) estudaram a CUT na sub-bacia do Córrego Maria Comprida, onde $81,6 \%$ da área é composta por Argissolos, e obtiveram resultados semelhantes ao do presente estudo. Os autores identificaram que $60 \%$ das terras são classificadas como classe $\mathrm{VI}$, tendo como principal fator limitante a declividade (15 a 45\%). Segundo os mesmos, aproximadamente metade da área agricultável estava sobreutilizada, ou seja, explorada além de sua capacidade de uso, incorrendo no risco de serem degradadas.

Algumas glebas, classificadas como classe IV, estavam sendo subutilizadas, pois estavam com mata nativa, podendo ser utilizadas para pastagens e cultivos anuais ocasionais, cultivos perenes limitados e culturas em rotação. Essas áreas podem ser utilizadas com autorização de corte pelo órgão ambiental e representam uma reserva de lenha e madeira para uso nas propriedades ou venda futura. Todavia, para fins de conservação do solo e possibilidade de pagamento por serviços ambientais foram considerados como em uso adequado.

Em algumas glebas, o uso com silvicultura foi classificado como sem conflito, por estar adequado para a classe de capacidade de uso $\mathrm{V}$, pois as terras desta classe têm limitações de uso, sendo apropriadas para pastagem, reflorestamento (silvicultura) ou preservação permanente.

\section{Percentual de Abatimento de Erosão}

O percentual de abatimento de erosão (Tabela 5) foi determinado com foco na manutenção de serviços ambientais e na possibilidade de retribuição por estes serviços. Como o sistema de manejo adotado na maior parte das glebas é o preparo de solo convencional, sem a adoção de práticas conservacionistas, os valores do percentual de abatimento de erosão refletem a alteração dos valores do parâmetro $Z$, sendo $Z_{0}$ o valor que corresponde ao uso e manejo convencional e $Z_{1}$ o valor resultante do uso adequado, aliado ao manejo conservacionista. 
Tabela 5 - Estimativa do percentual de abatimento da erosão para as glebas $(G)$ de três propriedades da bacia hidrográfica do arroio Epaminondas, Pelotas (RS), considerando a adoção de sistemas conservacionistas. Estimation of the percentage of erosion abatement for the plots $(G)$ of three properties in the Epaminondas stream, Pelotas (RS), considering the adoption of conservationist systems.

\begin{tabular}{|c|c|c|c|c|c|c|c|}
\hline & $\begin{array}{l}\text { Área } \\
\text { (ha) }\end{array}$ & CUT & $\begin{array}{c}\text { Uso atual } \\
\text { (verão /inverno) }\end{array}$ & $Z_{0}$ & $\begin{array}{c}\text { Uso indicado } \\
\text { (verão /inverno) }\end{array}$ & & $\begin{array}{l}\text { PAE } \\
(\%)\end{array}$ \\
\hline 1 & 14,73 & IVs & Silvicultura & 0,030 & Reflorestamento denso & 10 & 66,67 \\
\hline 2 & 0,38 & IVs & orticultura/Pousio de inverno & \multicolumn{4}{|c|}{ 0,375 Hortaliças em nível/Pastagem recuperada0,185 50,67 } \\
\hline 3 & 2,16 & Vs & Campo nativo & 0,250 & Pastagem recuperada & 0,12 & \\
\hline 4 & 0,47 & IIIs & Horticultura/P & \multicolumn{4}{|c|}{0,250 Hortaliças em nível/Pastagem recuperada0,185 26,00 } \\
\hline 5 & 0,20 & Vs & Campo nativo & 0,250 & Pastagem recuperada & 0,120 & 52,00 \\
\hline 6 & 0,20 & IVs & & \multicolumn{4}{|c|}{ 0,500 Hortaliças em nível/Pastagem recuperada0,185 63,00 } \\
\hline 7 & 0,17 & IIls & & \multicolumn{4}{|c|}{ 0,500 Hortaliças em nível/Pastagem recuperada0, 18563,00} \\
\hline 8 & 0,52 & IVs & Silv & 0,030 & Reflorestamento denso & 0,010 & 66,67 \\
\hline 9 & 0,09 & IVs & & \multicolumn{4}{|c|}{ 0,500 Hortaliças em nível/Pastagem recupe } \\
\hline 10 & 0 , & IVs & & \multicolumn{4}{|c|}{ 0,500 Hortaliças em nível/Pastagem recuperada0,185 63,00 } \\
\hline 11 & 0,08 & IIIs & ura/P & \multicolumn{4}{|c|}{0,375 Hortaliças em nível/Pastagem recuperada0,185 50,67 } \\
\hline 12 & 0,62 & IVs & & \multicolumn{4}{|c|}{0,500 Hortaliças em nível/Pastagem recuperada0,185 63,00 } \\
\hline 13 & 0,75 & IVs & & \multicolumn{4}{|c|}{ aliças em nível/Pastagem recuperada0, 18563,00} \\
\hline 14 & 0,25 & IVs & 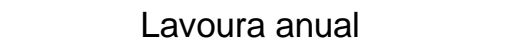 & 0,25 & grãos & \multicolumn{2}{|c|}{$0,10060,00$} \\
\hline 15 & 3,57 & \multicolumn{2}{|c|}{ IVs L } & & Pas & \multicolumn{2}{|c|}{$0,10060,00$} \\
\hline 16 & 0,26 & IVs & Lavo & & & \multicolumn{2}{|c|}{$0,10060,00$} \\
\hline 17 & 7,80 & IVs & anue & & & \multicolumn{2}{|c|}{$0,10060,00$} \\
\hline 18 & 0,41 & IVs & $M$ & - & & . & \\
\hline 19 & 0,41 & IVs & Mata nativa & & 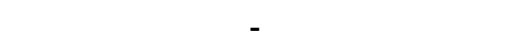 & - & 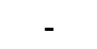 \\
\hline 20 & 4,98 & \multicolumn{3}{|c|}{ IVs Lavoura anual/Pousio de } & & \multicolumn{2}{|c|}{$0,10060,00$} \\
\hline 21 & 5,07 & & & & & \multicolumn{2}{|c|}{$0,10060,00$} \\
\hline 22 & 3,60 & & & 0 & Pas & \multicolumn{2}{|c|}{$0,10060,00$} \\
\hline 23 & 0,79 & IVs & Mata & - & & & \\
\hline 24 & 3,33 & Vs & & & & \multicolumn{2}{|c|}{$0,01066,67$} \\
\hline 25 & 1,14 & IVs & Silvicultura & 0,030 & Reflorestamento denso & \multicolumn{2}{|c|}{$0,01066,67$} \\
\hline
\end{tabular}

CUT: Capacidade de Uso da Terra; $Z_{0}$ : uso e manejo convencional, $Z_{1}$ : uso e manejo conservacionista; PAE: percentual de abatimento de erosão.

O percentual de abatimento da erosão estimado variou de 26 a $66,67 \%$, em função do tipo de uso, com média ponderada de $59,74 \%$. Da mesma forma, considerando a implantação de um projeto de pagamento por serviços ambientais, nos moldes do Programa Produtor de Água (PPA), poderia ocorrer redução média de $59,74 \%$ de erosão nas áreas agrícolas destas propriedades.

Em um trabalho desenvolvido por Ribeiro et al. (2007), com base no método proposto pelo PPA, foi feita uma estimativa do potencial de abatimento de erosão para a atividade agrossilvipastoril na unidade agroflorestal da Companhia Mineira de Metais, em Paracatu-MG, em Latossolo em relevo plano a suave ondulado. Os autores verificaram que o sistema permitiu abatimento da erosão correspondente a $78,52 \%$, em comparação a uma pastagem degradada. Chaves et al. (2004b), em um trabalho que quantificava benefícios ambientais e compensações financeiras do PPA, concluíram que, se aplicado a uma bacia rural supridora de água, como a do Ribeirão Pipiripau, no Distrito Federal, este programa aportaria benefícios significativos destacando-se abatimento médio da erosão de $73 \%$.

O PPA estabeleceu três faixas $(25-50 \%$, $51-75 \%$ e $>75 \%$ ) de abatimento de erosão, para determinar valores de referência de pagamento pelos serviços ambientais, para a conservação do solo. Os valores relativos a estas faixas devem ser definidos conforme o percentual de abatimento da erosão obtido pelo projeto executivo, multiplicado pela área que sofrer intervenção na propriedade (ANA, 2012). A maior parte das áreas do presente estudo se encontra na faixa de $51-75 \%$ de percentual de abatimento da erosão. Além deste parâmetro, existem outros importantes que devem ser considerados para a "produção de água", como a avaliação da qualidade da água nos açudes e cursos d'água da região. No presente estudo, não foram realizadas avaliações diretas da qualidade de água. Entretanto, a partir do percentual de abatimento da erosão é possível fazer inferências sobre esse aspecto, já que o processo de erosão hídrica pode causar o transporte de partículas de solo e de elementos tóxicos para corpos hídricos. Como orientação para a implantação de um pagamento por serviços ambientais, é preciso fazer análises da qualidade de água após a implantação das medidas corretivas em relação ao uso e manejo do solo.

O uso da terra mais representativo é composto por lavoura anual (culturas de verão) e pousio no inverno, representando $25,53 \%$ do uso agrícola, na área de estudo. Nessas áreas, o uso indicado foi com 
pastagens no inverno em rotação com culturas de grãos no verão. Dessa forma, a substituição desses usos, considerando inverno e verão, e do sistema convencional para plantio direto resultaram no maior percentual de abatimento da erosão (60\%).

A substituição do plantio convencional pelo sistema plantio direto, associado com cultivo em nível, com densa quantidade de palha e rotação de culturas poderá reduzir as perdas de solo por erosão e o assoreamento e contaminação dos corpos hídricos. No sul de Minas Gerais, Flauzino et al. (2016) aplicaram o sistema de classificação de uso da terra em uma bacia de, aproximadamente, $40 \mathrm{~km}^{2}$ com sérios problemas de erosão. Os autores chegaram à conclusão de que a principal causa de degradação na bacia hidrográfica era a ausência de técnicas de conservação do solo, apesar de metade da área ser coberta por pastagens, uso condizente à capacidade produtiva dos solos.

Algumas das glebas enquadradas na classe IV estão sobreutilizadas com cultivo anual de milho, em preparo convencional. Nessas áreas, após a colheita, a palha do milho permanece cobrindo o solo que, posteriormente, fica em pousio (período de inverno), porém sem práticas conservacionistas, como cultivo em nível ou rotação de culturas.

Outro uso bastante representativo na área é com silvicultura (19,72\%). Considerando o uso da silvicultura em espaçamentos menores $(2 \mathrm{~m} \times 2 \mathrm{~m}$ ou $2 \mathrm{~m} \times 3 \mathrm{~m}$ - linha $\times$ entrelinha) do que os que estão sendo utilizados, com linhas de cultivo em nível, se obtém um percentual de abatimento da erosão de aproximadamente $67 \%$. Segundo Servidoni et al. (2016), o planejamento da propriedade baseado na aplicação do sistema de capacidade de uso das terras é uma alternativa importante para melhorar a qualidade dos serviços ambientais, desde que se concilie a produção agropastoril ou agrossilvipastoril com o manejo conservacionista.

O uso da terra com hortaliças e pousio representa $2,82 \%$ da área agrícola em estudo. A maior parte desta área está classificada como classe IV. Para evitar o conflito de uso, recomenda-se a recuperação da pastagem nas áreas de pousio e o cultivo de hortaliças em nível, em rotação com plantas de cobertura e uso de resíduos orgânicos da propriedade, que, normalmente, têm altos teores de matéria orgânica, com implicação na retenção hídrica e de nutrientes. Os solos em estudo têm baixos teores de matéria orgânica e baixa capacidade de troca catiônica, por isso, se beneficiariam da adição maciça de resíduos orgânicos e da diminuição do revolvimento dos solos. Nessas áreas, a substituição do uso e a alteração no sistema de manejo pode promover um percentual de abatimento da erosão de, aproximadamente, 51\%.

O sistema plantio direto em hortaliças é bastante recomendado porque proporciona palhada suficiente para a proteção do solo e incorporação de nutrientes e manutenção da água. Segundo Lima et al. (2017), esse sistema preconiza o revolvimento mínimo do solo, restrito à cova ou linha de plantio; rotação ou sucessão de culturas e manutenção do solo coberto pelos resíduos vegetais de plantas de cobertura durante todo o ciclo de cultivo. Essas ações contribuem para a melhoria da qualidade do solo em termos nutricionais e quanto à redução da necessidade de água para irrigação, pois há menor perda de água no solo por evaporação), dentre outros, reduzindo os custos de produção. Os autores sugerem que parte da área deve ser destinada ao crescimento de plantas de cobertura em determinadas épocas do ano, enquanto outra parte seja destinada à produção da hortaliça. Dessa forma, percebe-se que a intensidade do uso da terra é um fator primordial que afeta a sua eficiência de uso e capacidade de suporte, por isso, é importante entender e descobrir os efeitos das mudanças no uso da terra em opções sustentáveis para sua gestão (Yan et al., 2017). Embora economicamente importantes nos sistemas de produção das propriedades estudadas, as hortaliças perfazem menos de $3 \%$ da área total, o que poderia ser um fator favorável ao uso da rotação de culturas e do sistema plantio direto propostos neste trabalho.

Dentre as alternativas de plantio climaticamente adequadas para a região, considerando também o custo e a disponibilidade de sementes, sugere-se a implantação de gramíneas (Poaceae) como aveia (Avena strigosa) no inverno, e de sorgo (Sorghum sp.), milho (Zea mays) ou milheto (Pennisetum americanum) no verão. Deve-se associar também o uso de leguminosas (Fabaceae) no sistema, como ervilhaca (Vicia sativa ou Vicia villosa), lab-lab (Lablab purpureus) e mucuna (Stizolobium sp) no verão.

O menor percentual de abatimento da erosão (26\%) se refere à gleba 4 (Tabela 5). Isso ocorre porque essa área tem menores restrições de uso, pois está classificada como classe III, e não está em conflito de uso. Em relação às áreas com mata nativa, não foram sugeridas alterações de uso, visando valorizar a conservação do solo e da água e a possibilidade de pagamento por serviços ambientais.

O sistema de CUT possibilitou não só classificar a capacidade de uso em cada área, como também indicar a importância do manejo adequado para uso mais racional do solo e consequente abatimento da erosão, evidenciando a possibilidade de adotar um sistema de Pagamento por Serviços Ambientais baseado no Percentual de Abatimento de Erosão. Dessa forma, os valores médios de percentual de abatimento da erosão poderiam ser utilizados para estabelecer uma ordem de prioridade para ações de mudança no uso e ou sistema de manejo entre as áreas estudadas.

A consideração da CUT pode levar ao incremento do percentual de abatimento de erosão, contribuindo para os serviços ambientais, por meio da conservação do solo e da água, além de ser de grande importância para incrementar a renda de produtores rurais que adotam atividades conservacionistas em suas propriedades e para a redução dos custos com manutenção de reservatórios e tratamento de água. $\mathrm{O}$ controle do uso da terra em locais de expansão urbana desordenada pode prevenir ou recuperar a degradação 
agroambiental. Para tanto, torna-se necessária a conscientização da sociedade e do poder público sobre a importância do uso sustentável dos recursos naturais e da conservação do solo e da água. Medidas de capacitação e sensibilização de produtores e extensionistas passam a ser vitais para a apropriação e aplicação das medidas preventivas e corretivas.

\section{Conclusões}

A profundidade efetiva e a presença de gradiente textural foram os principais fatores limitantes observados, responsáveis pela classificação de $87,69 \%$ da área na classe IV de capacidade de uso da terra.

Considerando que o conflito por sobreuso ocorreu em $53,42 \%$ da área, a substituição do uso atual por um manejo mais adequado à capacidade de uso da terra de cada área poderia contribuir para o melhor desempenho de serviços ambientais nas terras da bacia.

A implantação de um projeto de pagamento por serviços ambientais, como do Programa Produtor de Água, com mudança no uso da terra e substituição do cultivo convencional por sistemas conservacionistas, pode proporcionar redução média de $59,74 \%$ da erosão nessas áreas agrícolas.

A substituição do uso com lavoura anual, em sistema convencional, e pousio de inverno por rotação com culturas de grãos em sistema conservacionista e pastagens recuperadas pode resultar em 60\% de abatimento da erosão.

O uso de hortaliças em sistema convencional e pousio de inverno, adotado em áreas de classe IV de capacidade de uso, configura conflito de uso. Nestas áreas, a adoção da prática de plantio direto em hortaliças, com cultivo em nível e em rotação com plantas de cobertura, além da recuperação das pastagens, pode promover percentual de abatimento da erosão de, aproximadamente, $51 \%$.

\section{Agradecimentos}

Agradecemos o apoio da Coordenação de Aperfeiçoamento de Pessoal de Nível Superior (CAPES) e da Fundação de Amparo à Pesquisa do Estado do Rio Grande do Sul (FAPERGS), pela concessão de bolsa de estudos para realização desse trabalho.

\section{Referências}

Aires URV, Rezende CHS, Silva JLA, Campos JA, Santos CA (2017) Capacidade do uso da terra: um estudo de caso em uma microbacia do Rio Piracicaba, MG. Nativa 5(6):402-409 doi: 10.5935/23187670.v05n06a04
ANA Agência Nacional de Águas (2012) Programa Produtor de Água - Manual Operativo 2ed. Brasília: ANA 84p. Disponível em: <http://produtordeagua.ana.gov.br/Portals/0/DocsDNN 6/documentos/Manual\%20Operativo\%20Vers\%C3\%A 30\%202012\%20\%2001_10_12.pdf> (Acesso em: 06 jul 2020).

Bertoni, J.; Lombardi Neto, F. Conservação do solo. São Paulo: Ícone, 1990. 355 p.

Campos S, Cardoso LG, Campos M, Nardini RC, Rodrigues BT, Rodrigues MT, Tagliarini FSN, Traficante D (2016) Geoprocessamento aplicado no diagnóstico dos conflitos de uso e ocupação do solo em Áreas de Preservação Permanente no Ribeirão das AgulhasBotucatu (SP). InterEspaço: Revista de Geografia e Interdisciplinaridade 2(6):163-175. doi: http://dx.doi.org/10.18764/2446-

6549/interespaco.v2n6p163-175

Campos S, Nardini RC, Barros Z, Cardoso LG (2010) Sistema de informações geográficas aplicado à espacialização da capacidade de uso da terra. Pesquisa Agropecuária Tropical 40(2):174-179. doi:10.5216/pat.v40i2.3887

Chaves HML, Braga B, Domingues AF, Santos DG (2004a) Quantificação dos Benefícios Ambientais e Compensações Financeiras do "Programa do Produtor de Água" (ANA): I Teoria. Revista Brasileira de Recursos Hídricos 9(3):5-14. doi: 10.21168/rbrh.v9n3.p5-14

Chaves HML, Braga B, Domingues AF, Santos DG (2004b) Quantificação dos Benefícios Ambientais e Compensações Financeiras do "Programa do Produtor de Água" (ANA): II Aplicação. Revista Brasileira de Recursos Hídricos 9(3):15-21). doi: 10.21168/rbrh.v9n3.p15-21

Cunha CML, Pinton LG (2012) Avaliação da capacidade de uso da terra da bacia do córrego do cavalheiro - Analândia, SP. Geociências 31(3):459-471 Disponível em:

<http://www.ppegeo.igc.usp.br/index.php/GEOSP/article/view/7234> (Acesso em: 06 jul 2020).

De Maria, I. C.; Lombardi Neto, F. Razão de perdas de solo e fator $C$ para sistemas de manejo da cultura do milho. R. Bras. Ci. Solo, Campinas, v. 21, n. 2, pp. 263270, 1997.

Derpsch, R. Sustainable agriculture. In Saturnino; Landers (eds.). The environment and zero tillage. Brasília: APDC-FAO, p. 31-53, 2002. Disponível em: $<$ https://www.researchgate.net/profile/John_Landers3/publication/313426260_The_Environment_and Zero-Tillage/links/589a22c592851c8bb68213e2/TheEnvironment-and-Zero-Tillage.pdf > (Acesso em: 19 out 2020). 
Engel S, Pagiola S, Wunder S (2008) Designing payments for environmental services in theory and practice: An overview of the issues. Ecological Economics 65(4):663-674.

https://doi.org/10.1016/j.ecolecon.2008.03.011

Flauzino BK, Melloni EGP, Pons NAD, Lima O de (2016) Mapeamento da Capacidade de Uso da Terra como contribuição ao planejamento de uso do solo em sub- bacia hidrográfica piloto no sul de Minas Gerais. Geociências 35(2):277-287. Disponível em: <http://www.ppegeo.igc.usp.br/index.php/GEOSP/article/view/9025> (Acesso em: 06 jul 2020).

Flores CA, Alba JMF, Wrege MS (2009) Zoneamento Agroclimático do Eucalipto para o Estado do Rio Grande do Sul e Edafoclimático na Região do Corede Sul - RS. Pelotas: Embrapa Clima Temperado. 86p. Disponível $<$ https://ainfo.cnptia.embrapa.br/digital/bitstream/item/6 0138/1/13653.pdf> (Acesso em: 06 jul 2020).

Kreitlow JP, Silva JSV, Neves SMAS, Neves RJ, Neves LFS (2016) Vulnerabilidade ambiental e conflito no uso da terra no município de Mirassol d'Oeste, Brasil. Revista Brasileira de Cartografia 68(10):1917-1936. Disponível em:

<http://www.seer.ufu.br/index.php/revistabrasileiracarto grafia/article/view/44292> (Acesso em: 06 jul 2020).

Leprun, J.C. Manejo e Conservação de solos do Nordeste. Relatório de fim de Convênio de Manejo e Conservação do Solo do Nordeste Brasileiro (1982-83). Recife: Sudene-Orstom, 1983. 271 p.

Lepsch IF, Espindola CR, Filho OJV, Hernani LC, Siqueira, DS (2015) Manual para levantamento utilitário e classificação de terras no sistema de capacidade de uso. Viçosa, MG: SBCS. 170p.

Lima CEP, Madeira NR, Silva, J, Fontenelle MR, Melo RAC, Guedes IMR (2017) Benefícios da adoção do Sistema de Plantio Direto de Hortaliças. Brasília, DF: Embrapa Hortaliças, Documentos 156. 32p. Disponível em:

<https://ainfo.cnptia.embrapa.br/digital/bitstream/item/1 70160/1/DOC-156.pdf> (Acesso em: 06 jul 2020).

Lopes ICP, Campos JA (2019) Capacidade de uso da terra da sub-bacia do Córrego Maria Comprida usando Sistemas de Informações Geográficas. Journal of Environmental Analysis and Progress 4(2):110-121. doi: 10.24221/jeap.4.2.2019.2358.110-121
Margolis, E.; Silva, A. B.; Jaques, F. O. Determinação dos fatores da EUPS para as condições de Caruaru (PE). R. Bras. Ci. Solo, Campinas, v. 9, n. 2, pp. 165169, 1985.

Ribeiro JC, Anjos L HC dos, Pereira MG (2019) Aptidão e capacidade de uso das terras do Vale do Paraíba Paulista para o cultivo de Tectona grandis L. Revista Agrarian 12(44):182-195. doi: https://doi.org/10.30612/agrarian.v12i44.8944.

Ribeiro SC, Chaves HML, Jacovine LAG, Silva ML da (2007) Estimativa do abatimento de erosão aportado por um sistema agrossilvipastoril e sua contribuição econômica. Revista Árvore 31(2):285-293. doi: https://doi.org/10.1590/S0100-67622007000200011.

Rodrigues DBB, Sobrinho TA, Oliveira PTS de, Panachuki E (2011) Nova abordagem sobre o modelo Brasileiro de serviços ambientais. Revista Brasileira de Ciência do Solo 35(1):1037-1045. doi: 10.1590/S010006832011000300037

Santos HG, Jacomine PKT, Anjos LHC, Oliveira, VA, Lumbreras JF, Coelho MR, Almeida JÁ de, Araújo Filho JC, OLIVEIRA JB, CUNHA TJF (2018) Sistema brasileiro de classificação de solos. 5. ed. Brasília: Embrapa 353p.

Servidoni LE, Ayer JEB, Silva MLN, Spalevic V, Mincato RL (2016) Land use capacity and environment services. Revista Brasileira de Geografia Física 9(6):1712-1724. doi: 10.5935/1984-2295.20160119

Wischmeier WH, Smith DD (1978) Predicting rainfall erosion losses. Washington: USDA. 67p.

Wrege MS, Steinmetz S, Reisser Júnior C, Almeida IR (2012) Atlas climático da região Sul do Brasil: estados do Paraná, Santa Catarina e Rio Grande do Sul. Brasília: Embrapa. 333p. Disponível em: <https://www.embrapa.br/busca-de-publicacoes//publicacao/1045852/atlas-climatico-da-regiao-sul-dobrasil-estados-do-parana-santa-catarina-e-rio-grandedo-sul> (Acesso em: 06 jul 2020).

Yan H, Liu F, Liu J, Xiao X, Qin Y (2017) Status of land use intensity in China and its impacts on land carrying capacity. Journal of Geographical Sciences 27(4):387402. doi: $10.1007 / \mathrm{s} 11442-017-1383-7$ 